\title{
Paediatric cardiac transplantation with steroid-sparing maintenance immunosuppression
}

\author{
J Au, J W Gregory, I W Colquhoun, C D Scott, C J Hilton, S Hunter, J H Dark
}

Freeman Hospital,

Newcastle upon Tyne, Cardiopulmonary Transplant Unit

$\mathrm{J} \mathrm{Au}$

I W Colquhoun

C D Scott

C J Hilton

J H Dark

Department of Paediatric Cardiology

$S$ Hunter

Department of

Child Health,

Medical School,

Newcastle upon Tyne

J W Gregory

Correspondence to:

Cardiopulmonary

Transplant Unit,

High Heaton,

Newcastle upon Tyne

NE7 7DN.

Accepted 14 May 1992
$\mathrm{Mr} \mathrm{J} \mathrm{Au}$,

Freeman Hospital,

\begin{abstract}
In order to determine the results of steroidsparing maintenance immunosuppression in paediatric patients who have undergone orthotopic heart transplantation (OHT), a retrospective study was undertaken in 12 children and five infants (median age 3.5 years). Preoperative diagnoses were cardiomyopathy in seven and congenital heart disease in 10 patients. Immunosuppression was induced by cyclosporin, azathioprine, methylprednisolone, and antihuman lymphocyte immune globulin. It was maintained with cyclosporin and azathioprine. After induction, five patients received no further steroids. The remainder, except one, required only pulses for rejection (13 episodes or 0.51 episodes/ patient year). Long term complications included hypertension in six, and renal impairment in three children. There were no early or late deaths from infection. Actuarial survival was $94 \%$ at one year. Of the children followed up for more than one year, all demonstrated an increase in height SD scores (mean (SD) $-2.15(1.35)$ to $-1.15(1 \cdot 16)$ ). We conclude that a steroid-sparing maintenance immunosuppression regimen can be successfully employed in paediatric OHT, and that significant catch-up growth can be achieved postoperatively.
\end{abstract}

\section{(Arch Dis Child 1992;67:1262-6)}

Cardiac transplantation is now an accepted form of treatment for infants and children with end stage cardiac disease. Since 1984 more than 1100 such procedures have been performed worldwide in children up to the age of 18 years, and cardiac transplantation in infants younger than 1 year old has been the most rapidly

Table 1 Details of paediatric cardiac transplant recipients

\begin{tabular}{|c|c|c|c|c|c|c|}
\hline $\begin{array}{l}\text { Case } \\
\text { No }\end{array}$ & Diagnosis & $\begin{array}{l}\text { Previous } \\
\text { surgery }\end{array}$ & Age & PVRI & $\begin{array}{l}\text { Donor: } \\
\text { recipient }\end{array}$ & Inotropes \\
\hline $\begin{array}{r}1 \\
2 \\
3 \\
4 \\
5 \\
6 \\
7 \\
8 \\
9 \\
10 \\
11 \\
12 \\
13 \\
14 \\
15 \\
16 \\
17\end{array}$ & $\begin{array}{l}\text { Cardiomyopathy } \\
\text { CHD } \\
\text { Cardiomyopathy } \\
\text { CHD } \\
\text { Cardiomyopathy } \\
\text { CHD } \\
\text { Cardiomyopathy } \\
\text { CHD } \\
\text { CHD } \\
\text { CHD } \\
\text { CHD } \\
\text { CHD } \\
\text { CHD } \\
\text { Cardiomyopathy } \\
\text { Cardiomyopathy } \\
\text { Cardiomyopathy } \\
\text { CHD }\end{array}$ & $\begin{array}{l}\overline{\text { Yes }} \\
\overline{\text { Yes }} \\
\overline{\text { Yes }} \\
\overline{\text { No }} \\
\text { Yes } \\
\text { Yes } \\
\text { Yes } \\
\text { No } \\
\text { Yes } \\
\overline{-} \\
\overline{\bar{N}}\end{array}$ & $\begin{array}{l}5 \text { months } \\
2 \cdot 4 \text { years } \\
8 \text { years } \\
8 \cdot 1 \text { years } \\
12 \cdot 2 \text { years } \\
11 \text { years } \\
9 \cdot 7 \text { years } \\
5 \text { weeks } \\
4 \cdot 8 \text { years } \\
3 \text { years } \\
3 \cdot 5 \text { years } \\
3 \text { years } \\
8 \text { years } \\
5 \cdot 4 \text { months } \\
9 \cdot 2 \text { months } \\
10 \text { weeks } \\
3 \cdot 7 \text { years }\end{array}$ & $\begin{array}{l}3.6 \\
-\quad 6.7 \\
1.4 \\
<1 \\
3.0 \\
4.8 \\
-5.0 \\
-\quad \\
2.1 \\
4.5 \\
1.6 \\
3.0 \\
-\end{array}$ & $\begin{array}{l}1.3 \\
1.3 \\
1.3 \\
1.5 \\
0.9 \\
1.4 \\
1.1 \\
\frac{2}{2 \cdot 2} \\
1.9 \\
1.6 \\
1.7 \\
1.2 \\
2 \cdot 1 \\
1.1 \\
1.8 \\
1.1\end{array}$ & $\begin{array}{l}\text { Yes, ventilated } \\
\text { No } \\
\text { No } \\
\text { No } \\
\text { No } \\
\text { No } \\
\text { Yes } \\
\text { Yes, ventilated } \\
\text { No } \\
\text { No } \\
\text { No } \\
\text { No } \\
\text { No } \\
\text { Yes } \\
\text { Yes } \\
\text { Yes, ventilated } \\
\text { No }\end{array}$ \\
\hline
\end{tabular}

$\mathrm{CHD}=$ congenital heart disease, $\mathrm{PVRI}=$ pulmonary vascular resistance index.

"Donor: recipient weight ratio. growing area during the last five years.' Actuarial survival of $72 \%$ at one year and $60 \%$ at five years is being achieved internationally. ${ }^{2}$ The improved survival of cardiac transplant recipients with cyclosporin based immunosuppression is well established, but controversy remains as to whether steroids should be used in the paediatric patient, particularly in view of its long term side effects in this age group. ${ }^{2}{ }^{3}$ Since the inception of our paediatric cardiac transplant programme in 1987, we have adopted a steroidsparing regimen for maintenance immunosuppression. This report summarises our experience in 17 children under the age of 13 years who have received an orthotopic heart transplant (OHT).

\section{Patients and methods}

Between October 1987 and August 1991, 17 OHTs have been performed in 17 children at the Freeman Hospital, Newcastle upon Tyne. The patients ranged in age from 5 weeks to $12 \cdot 2$ years (median 3.5 years), with five infants under the age of 1 year. Patient details are illustrated in table 1. The preoperative diagnoses were cardiomyopathy in seven children and congenital heart disease in 10. Of the latter, seven had previously had closed heart surgery: four had pulmonary artery banding and three had systemic to pulmonary arterial shunts. Six children were in hospital and dependent on inotropes, and three were ventilator dependent before OHT. Sixteen of the 17 children survived OHT and have been followed up from 38 days to 3.8 years (median 1.4 years). The case records of these children were reviewed to determine the incidence of rejection, hospital admissions for intercurrent illnesses, and late complications. Growth data was available from standing height measurements in 11 children who had been followed up for more than one year. For comparative purposes, height and velocity were expressed as SD scores. ${ }^{4}$ Renal function was assessed by a calculated glomerular filtration rate (GFR) based on Barratt's formula. ${ }^{5}$ This formula is only applicable to children older than 6 months: a figure of $>80$ $\mathrm{ml} / \mathrm{min} / 1 \cdot 73 \mathrm{~m}^{2}$ was taken to indicate normal GFR.

\section{IMMUNOSUPPRESSION}

Immunosuppression was induced by the oral administration of cyclosporin $10 \mathrm{mg} / \mathrm{kg}$ and intravenous administration of azathioprine $4 \mathrm{mg} / \mathrm{kg}$ two hours before OHT. Peroperatively, methylprednisolone $10 \mathrm{mg} / \mathrm{kg}$ was given intra- 
venously at the end of cardiopulmonary bypass, and three further doses of $2 \mathrm{mg} / \mathrm{kg}$ were given at eight hourly intervals in the first 24 hours. The postoperative immunosuppression regimen consisted of oral cyclosporin $(8 \mathrm{mg} / \mathrm{kg} /$ day $)$, oral azathioprine (1-3 mg/kg/day), and intravenous antilymphocyte globulin (Lymphoglobulin, Institut Mérieux, $5 \mathrm{ml} / 10 \mathrm{~kg} /$ day) for the first seven days. Cyclosporin dosage was adjusted to maintain a trough concentration of $400 \mathrm{ng} / \mathrm{ml}$ (radioimmunoassay for whole blood, Incstal Ltd) for the first six weeks, reducing to $200 \mathrm{ng} /$ $\mathrm{ml}$ thereafter. Azathioprine dosage was adjusted to maintain the white cell count greater than $4 \times 10^{9} / 1$. Steroids were not used for maintenance immunosuppression. Prophylactic flucloxacillin was given in the early postoperative period. Broad spectrum antibiotic cover was avoided for prophylaxis or treatment. Sulphamethoxazoletrimethoprim (three days per week), acyclovir, and nystatin were administered orally for 12 weeks as prophylaxis against Pneumocystis carinii, herpes simplex, and candida respectively.

\section{REJECTION SURVEILLANCE AND TREATMENT}

Non-invasive rejection surveillance via cross sectional and $\boldsymbol{M}$ mode echocardiography was the norm, supplemented by endomyocardial biopsy in suspicious cases in children older than 1 year. Echocardiography was performed twice weekly for six weeks, at weekly intervals thereafter until 12 weeks, fortnightly intervals thereafter until six months, monthly intervals thereafter until 1 year, and then every six weeks indefinitely, or as clinically indicated. A reduction in fractional shortening, an increase in left ventricular wall thickness, or the detection of a new pericardial effusion were taken as signs of rejection. Rejection was diagnosed whenever these signs were associated with clinical features of rejection-that is, unexplained fever or weight gain, lethargy, irritability, poor feeding, arrhythmia, gallop rhythm, or congestive failure-and confirmed by an appropriate response to treatment.
Intravenous methylprednisolone $(10 \mathrm{mg} / \mathrm{kg})$ for three days was given for rejection within the first six weeks. This was followed by oral prednisolone $(1 \mathrm{mg} / \mathrm{kg})$ which was generally tapered off over three to four weeks. Rejection occurring after the first six weeks was treated likewise with oral prednisolone unless it was severe, in which case steroids would be given intravenously. All our patients have responded to augmented steroids: we have not had to resort to antithymocyte globulin or $\mathrm{OKT}_{3}$ or refractory rejection.

\section{CORONARY ANGIOGRAPHY}

Coronary angiography is performed electively at yearly intervals from the second year onwards.

\section{STATISTICAL METHODS}

Comparison of the ages of rejectors and nonrejectors was performed with the Mann-Whitney $\mathrm{U}$ test. Univariate analysis of rejection by age was with Fisher's exact test. Height SD score at transplant and one year after were compared using the Wilcoxon signed rank test. Statistical significance was taken at the $5 \%$ level. Actuarial survival was calculated according to the method of Kaplan and Meier. ${ }^{6}$

\section{Results}

After induction of immunosuppression, five patients did not receive any more steroids. All remaining children required pulses for rejection. Of these, two required a prolonged low dose prednisolone tail for continuing mild rejection: one is now off steroids and has remained free of rejection for six months, the other is currently still on prednisolone $0.1 \mathrm{mg} / \mathrm{kg} /$ day. Five patients did not tolerate azathioprine and are currently maintained on cyclosporin alone.

Table 2 illustrates early and late complications and survival data. Actuarial survival was $94 \%$ at one year. Thirteen episodes of rejection requiring treatment were diagnosed by echocardiography with or without endomyocardial biopsy $(0.51$

Table 2 Follow up data on paediatric cardiac transplant recipients

\begin{tabular}{|c|c|c|c|c|c|c|c|}
\hline \multirow{2}{*}{$\begin{array}{l}\text { Case } \\
\text { No }\end{array}$} & \multirow{2}{*}{$\begin{array}{l}\text { Ischaemic } \\
\text { time } \\
\text { (min) }\end{array}$} & \multirow{2}{*}{$\begin{array}{l}\text { Perioperative } \\
\text { complications }\end{array}$} & \multicolumn{2}{|c|}{ Rejection episodes } & \multirow{2}{*}{$\begin{array}{l}\text { Hypertension } \\
\text { (late) }\end{array}$} & \multirow{2}{*}{$\begin{array}{l}\text { Renal } \\
\text { function } \\
\left(\text { ml } / \text { min } / 1 \cdot 73 \mathrm{~m}^{2}\right)\end{array}$} & \multirow[t]{2}{*}{ Survival } \\
\hline & & & $<3$ months & $>3$ months & & & \\
\hline 1 & 69 & $\begin{array}{l}\text { Staphylococcal } \\
\text { septicaemia, } \\
\text { gastroenteritis }\end{array}$ & - & - & No & 148 & 3.8 years \\
\hline 2 & 89 & - & 1 & - & No & 54 & 3.4 years \\
\hline 3 & 210 & CMV infection & - & - & No & 57 & $3 \cdot 1$ years \\
\hline 4 & 206 & - & 1 & - & No & 86 & $2 \cdot 1$ years \\
\hline 5 & 168 & - & i & - & Yes & 71 & 1.9 years \\
\hline 6 & 220 & Convulsions & - & - & No & 83 & 1.7 years \\
\hline 7 & 170 & Left hemiparesis & 1 & 2 & Yes & 115 & 1.6 years \\
\hline 8 & 176 & Donor failure & - & - & - & - & DOT \\
\hline 9 & 271 & - & - & 1 & Yes & 166 & 1.4 years \\
\hline 10 & 137 & Hypertension & 1 & - & No & 112 & 1.3 years \\
\hline 11 & 220 & & & 1 & No & 90 & $1 \cdot 2$ years \\
\hline 12 & 72 & $\begin{array}{l}\text { Hypertension, urinary } \\
\text { tract infection }\end{array}$ & 1 & - & No & 109 & $1 \cdot 1$ years \\
\hline 13 & 226 & $\begin{array}{l}\text { Bleeding (reoperated), } \\
\text { fits (hypertensive } \\
\text { encephalopathy) }\end{array}$ & 1 & 1 & Yes & 91 & 12.5 months \\
\hline 14 & 184 & $\begin{array}{l}\text { Line sepsis, } \\
\text { gastroenteritis }\end{array}$ & 1 & - & No & 135 & $9 \cdot 8$ months \\
\hline 15 & 164 & $\begin{array}{l}\text { Hypertension, line } \\
\text { sepsis }\end{array}$ & - & 一 & Yes & 83 & $7 \cdot 4$ months \\
\hline $\begin{array}{l}16 \\
17\end{array}$ & $\begin{array}{l}213 \\
173\end{array}$ & $\begin{array}{l}\text { Hypertension } \\
\text { PUO }\end{array}$ & 二 & $\overline{N A}$ & $\begin{array}{l}\text { Yes } \\
\text { No }\end{array}$ & $\begin{array}{l}\text { NA } \\
101 \cdot 5\end{array}$ & $\begin{array}{l}79 \text { days } \\
38 \text { days }\end{array}$ \\
\hline
\end{tabular}

$\mathrm{CMV}=$ cytomegalovirus, $\mathrm{DOT}=$ died on table, $\mathrm{NA}=$ not applicable, $\mathrm{PUO}=$ pyrexia of unknown origin. 
episodes/patient year); eight occurred within the first three months of OHT $(0 \cdot 17$ episodes/ patient month). Of 13 episodes of treated rejection, four were diagnosed on clinical and echocardiographic grounds alone. Endomyocardial biopsies were performed in the remaining nine episodes: moderate rejection according to the Billingham classification ${ }^{7}$ was confirmed on four occasions, mild rejection on four, and minimal rejection on one occasion. Six patients (including three infants) never rejected. There was no significant difference between the mean age of the non-rejectors and that of the rejectors (4 $v 5.5$ years, $p>0.05$ ), nor was there any significant difference between the number of rejection episodes in the first month among the infants when compared with older children ( $\mathrm{p}>0.05)$.

Paediatric OHT patients were admitted to hospital 3.54 times/patient year (fig 1). Most commonly, admissions were for the diagnosis of unexplained fever and the exclusion of rejection. The usual childhood infections were tolerated well, and did not appear to occur with undue frequency. Apart from a single episode of staphylococcal septicaemia in the perioperative period, life threatening infections have not been a problem.

By contrast, hypertension has been a significant early and late complication requiring treatment. Five children developed early postoperative hypertension, one complicated by hypertensive encephalopathy with convulsions. Not all of these children required long term antihypertensive treatment, however: two remained normotensive despite discontinuation of their treatment. The remaining three children, and three others who became hypertensive on follow up, required long term antihypertensive treatment.

Three children had impaired renal function as assessed by Barratt's formula, with an estimated GFR $<80 \mathrm{ml} / \mathrm{min} / 1 \cdot 73 \mathrm{~m}^{2}$ (table 2 ). All three children had normal preoperative renal function, although one child had documented reflux nephropathy.

Coronary angiography was performed on four children who have survived for two years or more. To date we have not detected any evidence of accelerated graft coronary disease.

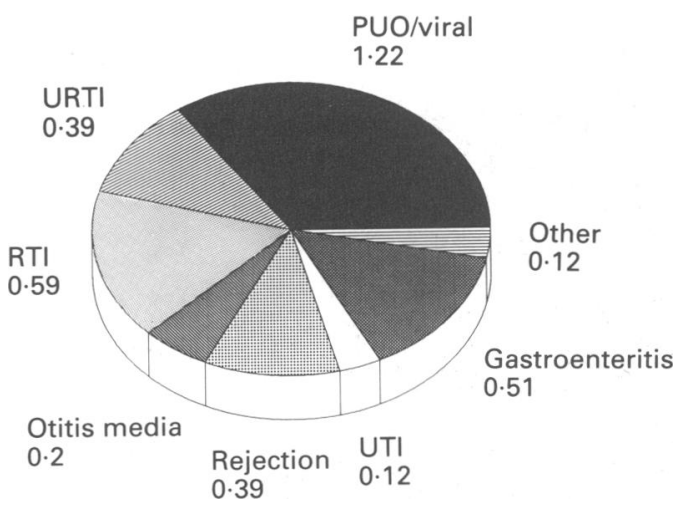

Figure 1 Hospital admissions for paediatric cardiac transplant recipients (linearised rate/patient year). $P U O=$ pyrexia of unknown origin, $R T I=$ respiratory tract (chest) infection, $U R T I=u p p e r$ respiratory tract infection, $U T I=$ urinary tract infection.

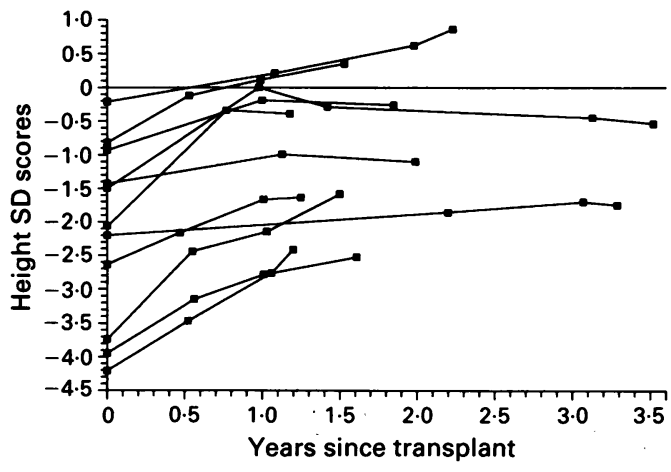

Figure 2 Growth after paediatric cardiac transplant.

Progressive changes in height SD score after OHT are shown in figure 2. All patients demonstrated an initial increase in height SD score, with the mean (SD) height SD score increasing significantly from $-2 \cdot 15(1 \cdot 35)$ to $-1 \cdot 15(1 \cdot 16)$ during the first year after transplantation $(p<0 \cdot 005)$. Mean (SD) height velocity during the first year was $10 \cdot 3(2 \cdot 2) \mathrm{cm} /$ year and height velocity SD score was $4 \cdot 11(2 \cdot 03)$. Overall, patients with cardiomyopathy were taller before transplantation than patients with congenital heart disease (height SD score $-1.48(0.69) v-2.41(1.48)$, and attained a smaller height velocity response during the first year after transplantation (height velocity 8.53 (2.56) $v 10.99(1.78) \mathrm{cm} /$ year; height velocity SD score $3.32(3.6) v 4 \cdot 4(1 \cdot 34))$. However, sample sizes are small and none of the differences achieved statistical significance. Likewise, a meaningful statement cannot be made regarding postoperative growth in patients who received pulsed steroids when compared with those who did not, as only one patient has been followed up for more than one year in the latter group. All patients currently enjoy a good quality of life, although one patient is showing significantly delayed psychomotor development.

\section{Discussion}

Yacoub et al, in 1985, reported initial results of steroid-sparing immunosuppression in 67 patients, with an actuarial survival rate of $82 \%$ at one year. ${ }^{8}$ Subsequently, two prospective, randomised clinical trials have been performed in adults. ${ }^{910}$ Both studies reported an increased incidence of rejection on a steroid-sparing regimen, with possible benefits in terms of a reduction in the incidence of hypertension, serious infections, and the development of diabetes. A recent survey of paediatric heart transplant practice in the USA showed that $74 \%$ of centres used steroid-based maintenance immunosuppression (cyclosporin, prednisolone, azathioprine), $17 \%$ used cyclosporin and prednisolone, and $26 \%$ used steroid-sparing regimens. ${ }^{2}$ Since the inception of our paediatric cardiac transplant programme in 1987, we have adopted a steroid-sparing maintenance immunosuppression regimen, consequent upon our concern about the effects of steroids on growth and infection in this age group. We present in this report the medium term results of our regimen in 16 children who have survived orthotopic heart transplantation. 
SURVIVAL

Of the 17 children, one died in the immediate postoperative period of primary donor organ failure. All other children in this series have survived OHT and are alive at current follow up. Actuarial survival at one year is $94 \%$. The risk of paediatric OHT is documented to be higher than adult OHT: operative mortality is $24 \%$ in children $\leqslant 4$ years and $16 \%$ in children 5-9 years. ${ }^{1}$ Donor organ preservation failure, donor right heart failure associated with recipient pulmonary hypertension, difficulty in reconstructing complicated pulmonary artery anatomy, and haemorrhage are often responsible. ${ }^{11}$ There seems to be general consensus that OHT is contraindicated if the pulmonary vascular resistance index (PVRI) is greater than 5-6 Wood units $/ \mathrm{m}^{2}$ despite pharmacological manipulation ${ }^{12-14}$; the risk becomes prohibitively high if this is associated with preoperative inotrope dependency. ${ }^{12}$ The majority of our patients with congenital heart disease had a 'protected' pulmonary circulation by virtue of their pulmonary artery banding or pulmonary stenosis, and only one of our patients with cardiomyopathy had a PVRI of $>6$. These factors may explain at least in part our excellent operative mortality. On the other hand, we have not had any technical deaths attributable to previous pulmonary artery banding (four children) or systemic-pulmonary shunting (three children).

\section{REJECTION}

Table 3 compares the linearised incidence of rejection in our patients with those figures published by other centres. The different series are not directly comparable, as the age composition of the patient groups is different and the method of rejection surveillance dissimilar. Nevertheless the various incidences are within the same order of magnitude, regardless of whether steroid-sparing or steroid-based maintenance immunosuppression was employed. The real question is whether the tendency to reject is the same in infancy, childhood, and adolescence. Animal experiments suggest that the host immune response is less aggressive and more easily controlled shortly after birth, and clinical observations have confirmed that the newborn infant (0-30 days) may be immunologically the best possible recipient of a cardiac allograft. ${ }^{16}$ Other workers have reported that rejection occurred more commonly in adolescents than in children and infants, ${ }^{17}$ although we have not found a significant difference in the frequency of rejection between infants and older children. We have, however, experienced difficulty in

Table 3 Linearised rejection incidences in published series

\begin{tabular}{|c|c|c|c|c|c|}
\hline \multirow[t]{2}{*}{ Series } & \multirow[t]{2}{*}{ Mean age } & \multicolumn{2}{|c|}{ Episodes/patient month } & \multirow{2}{*}{$\begin{array}{l}\text { Immunosuppression } \\
\text { regimen }\end{array}$} & \multirow{2}{*}{$\begin{array}{l}\text { Rejection } \\
\text { surveillance }\end{array}$} \\
\hline & & lst month & 1 st 3 months & & \\
\hline $\begin{array}{l}\text { Current } \\
\text { Loma Linda }^{15} \\
\text { Pittsburgh } \\
\text { Stanford }\end{array}$ & $\begin{array}{l}3.8 \text { years } \\
1.8 \text { months } \\
9 \text { years } \\
7.4 \text { years }\end{array}$ & $\begin{array}{l}0 \cdot 38 \\
0 \cdot 82 \\
0 \cdot 7 \\
0 \cdot 67\end{array}$ & $\begin{array}{l}0.17 \\
0.71 \\
\overline{(0.34) t}\end{array}$ & $\begin{array}{l}\text { CA } \\
\text { CA/C } \\
\text { CPA } \\
\text { CPA }\end{array}$ & $\begin{array}{l}\text { Non-invasive } \\
\text { Non-invasive } \\
\text { ? } \\
\text { Biopsy }\end{array}$ \\
\hline
\end{tabular}

$\mathrm{C}=$ cyclosporin; $\mathrm{A}=$ azathioprine; $\mathrm{P}=$ prednisolone.

${ }^{*}$ First year of life only, biopsy thereafter; third month. weaning two of our older children from steroids after augmented immunosuppression for rejection, and other workers have had similar experiences. ${ }^{1118}$ Significantly, late deaths from rejection have been reported in most published series involving older children ${ }^{11} 11^{19}$ but not infants. ${ }^{15} 2021$ These observations support the concept of a 'window of opportunity' in neonatal, ${ }^{22}$ and perhaps early childhood transplantation, which may be reflected by the satisfactory control of rejection with a less aggressive immunosuppressive regimen.

\section{LATE COMPLICATIONS}

The most frequent late complications in paediatric OHT are infection, hypertension, renal impairment, and growth retardation. ${ }^{19}$ Of greater concern, although occurring less frequently, are malignancies and coronary artery disease.

In common with some other published series $^{17} 1920$ there were no late deaths due to infection in our patients. However, this cannot be attributed to our steroid-sparing maintenance regimen as similar results have been reported with steroid-based maintenance immunosuppression. ${ }^{17}{ }^{19}$ Minor infections and undiagnosed fever were common reasons for hospital admissions among our patients. These admissions were more precipitated by the spectre of rejection and overwhelming infection than the severity of the illness, and it is pertinent to note that neither has been a problem beyond the first year. Nevertheless, two children have had troublesome and persistent chest infections requiring recurrent admissions and prolonged courses of antibiotics. Like others, we have not noted a greater frequency of minor ailments in our patients over that of children in the general population. ${ }^{23}$

Hypertension is a common adverse effect of cyclosporin treatment, ${ }^{3}$ which may be potentiated by steroids. ${ }^{24}$ It has been reported to occur in $40-96 \%$ of children undergoing OHT. ${ }^{18} 19$ Our experience is in accord with the former figure. Nephrotoxicity is another common adverse effect of cyclosporin, ${ }^{25}$ although long term renal impairment may not be as great a problem as feared. ${ }^{16} 1826$ Indeed, a recent report suggests that renal function can be preserved in paediatric patients if the whole blood trough concentration was maintained between 100 and $200 \mathrm{ng} / \mathrm{ml}^{27}$ However, all three children with estimated GFR $<80 \mathrm{ml}$ $\min / 1.73 \mathrm{~m}^{2}$ in our series had normal preoperative renal function, although one had documented reflux nephropathy.

At the time of OHT, our patients were substantially shorter than normal. This may be due to the multifactorial, though well recognised, adverse effect of cardiac failure on growth. ${ }^{28}$ In all our patients in whom adequate growth data is available, catch-up growth is observed during the first year after transplantation. While surgical correction of congenital heart disease frequently improves growth ${ }^{29}$ there is limited and conflicting data on the effects of OHT. With steroid-based maintenance immunosuppression, some groups have reported growth 
retardation in up to $75 \%$ of children younger than 14 years, ${ }^{26}$ while others have demonstrated normal growth after transplantation. ${ }^{11} 19$ The use of steroids for cumulative periods of more than one month, at two or more times the physiological replacement dose, has been implicated in those children with unsatisfactory growth after transplantation. ${ }^{30}$ Therefore, the use of a steroid-sparing maintenance immunosuppression regimen may in part explain the excellent initial growth response observed in our patients after OHT. Nevertheless, after the first year, our patients as a group remain shorter than normal, and the catch-up effect appears to wane. Further analysis of the data is limited by the lack of bone age measurements: it remains to be seen with prolonged follow up whether these children have a normal growth potential, but with some constitutional delay.

Finally, the occurrence of accelerated arteriosclerosis and lymphoproliferative diseases in paediatric OHT patients is well established, ${ }^{11} 1931$ although we have not, as yet, noted either in our patients. The use of steroids may theoretically contribute to the former, ${ }^{3}$ while the use of cyclosporin and azathioprine is known to be associated with the latter. It remains to be seen whether a steroid-sparing maintenance immunosuppression regimen will result in reduced graft coronary artery disease in this age group, although there is evidence in adults that this may be so. ${ }^{32}$

\section{CONCLUSION}

These results confirm that a steroid-sparing maintenance immunosuppression regimen consisting of cyclosporin and azathioprine can be successfully used in paediatric OHT, with acceptable early and late morbidity. Potential benefits include improved growth. Further follow up is required to determine if this regimen results in a reduced incidence of accelerated graft coronary artery disease.

1 Kriett JM, Kaye MP. The Registry of the International Society for Heart and Lung Transplantation: eighth official report-1991. Fournal of Heart and Lung Transplantation 1991;10:491-8.

2 Pennington DG, Noedel N, McBride LR, Naunheim KS, Ring S. Heart transplantation in children: an international Ring S. Heart transplantation in children:
survey. Ann Thorac Surg 1991;52:710-5.

3 Cameron DE, Traill TA. Complications of immunosuppressive therapy. In: Baumgartner WA, Reitz BA, Achuff SC, sive therapy. In: Baumgartner WA, Reitz BA, Achuff SC, eds. Heart and heart-lung transplantant

4 Tanner JM, Whitehouse RH, Takaishi M. Standards from birth to maturity for height, weight, height velocity and weight velocity: British children, 1965. Part II. Arch Dis Child 1966;41:613-35.

5 Counahan R, Chantler C, Ghazali S, Kirkwood B, Rose F, Barratt TM. Estimation of glomerular filtration rate from plasma creatinine concentration in children. Arch Dis Child plasma creatining

6 Kaplan EL, Meier P. Nonparametric estimation from incomplete observations. American Statistical Association incomplete observations.

7 Billingham ME. Diagnosis of cardiac rejection by endomyocardial biopsy. F Heart Transplant 1985;1:25-30.

8 Yacoub M, Alivizatos P, Khaghani A, Mitchell A. The use of cyclosporin, azathioprine, and antithymocyte globulin with or without low-dose steroids for immunosuppression of cardiac transplant patients. Transplant Proc 1985;XVII: 221-2.

9 Esmore DS, Spratt PM, Keogh AM, Chang V. Cyclosporine and azathioprine immunosuppression without maintenance steroids: a prospective randomized trial. $\mathcal{F}$ Heart Transplant 1989;8:194-9.

10 Szentpetery S, Richardson J, Hanrahan J, Lower RR. Cardiac transplantation witout oral steroids. The McGuire VA Hospital experience. $\mathcal{F}$ Heart Transplant 1989;8:103.

11 Trento A, Griffith BP, Fricker FJ, Kormos RL, Armitage J, Hardesty RL. Lessons learned in pediatriuc heart transplantation (discussion). Ann Thorac Surg 1989;48:617-23.

12 Addonizio LJ, Hsu DT, Fuzesi L, Smith CR, Rose EA. Optimal timing of pediatric heart transplantation. CirculaOptimal timing of pediatric hea
tion 1989;80 (suppl III):84-9.

13 Bailey LL. Pediatric heart transplantation. Ann Thorac Surg 1989;48:612

14 Starnes VA, Bernstein D, Oyer PE, et al. Heart transplantation in children. $\mathcal{F}$ Heart Transplant 1989;8:20-6.

15 Boucek MM, Kanakriyeh MS, Mathis CM, Trimm III RF, Bailey LL. Cardiac transplantation in infancy: donors and recipients. F Pediatr 1990;116:171-6.

16 Bailey LL, Assaad AN, Trimm F, et al. Orthotopic transplantation during early infancy as therapy for incurable congenital heart disease. Ann Surg 1988;208:279-86.

17 Braunlin EA, Canter CE, Olivari MT, Ring WS, Spray TL, Bolman III RM. Rejection and infection after paediatric cardiac transplantation. Ann Thorac Surg 1990;49:385-90.

18 Starnes VA, Stinson EB, Oyer PE, et al. Cardiac transplantation in children and adolescents. Circulation 1987;76 (suppl V): V43-7.

19 Addonizio LJ, Hsu DT, Smith CR, Gersony WM, Rose EA. Late complications in pediatric cardiac transplant Late complications in pediatric cardiac trans
recipients. Circulation 1990;82 (suppl IV):IV295-301.

20 Bailey LL, Wood M, Razzouk A, Arsdell GV, Gundry S. Heart transplantation during the first 12 years of life. Arch Surg 1989;124:1221-6.

21 Hehrlein FW, Netz $\mathrm{H}$, Moosdorf $\mathrm{R}$, et al. Pediatric heart transplantation for congenital heart disease and cardiomyopathy. Ann Thorac Surg 1991;52:112-7.

22 Nehlsen-Cannarella $S$. The unique newborn immune response. Fournal of Heart and Lung Transplantation 1991; 10:828-30.

23 Cutler D. Infant infections and immune response. Proceedings of the Loma Linda International Conference on Pediatric Heart Transplantation. Palm Desert, California, 1990. Fournal of Heart and Lung Transplantation 1991;10: 852-3.

24 Forman SJ, Textor SC, Carlson JE. Prednisone potentiates cyclosporine induced blood pressure changes in normotencyclosporine induced blood pressure changes in normoten297.

25 Myers BD, Ross J, Newton L, Luetscher J, Perlroth M. Cyclosporin-associated chronic nephropathy. $N$ Englf Med 1984;311:699-70

26 Starnes VA. Risks of childhood immunosuppression. Fournal of Heart and Lung Transplantation 1991;10:832-4.

27 Robitaille P, Chartrand S, Stanley P, Chartand C. Long-term assessment of renal function under cyclosporin in pediatric transplant recipients. Fournal of Heart and Lung Transplantation 1991;10:460-3.

28 Bayer LM, Robinson SJ. Growth history of children with congenital heart defects. Am $\mathcal{F}$ Dis Child 1969;117:564-72.

29 Mehrizi A, Drash A Growth disturbance in congenital heart disease. F Pediatr 1962;61:418-29.

30 Baum MF. Infant growth. Proceedings of the Loma Linda International Confererence on Pediatric Heart Transplantation. Palm Desert, California, 1990. Fournal of Transplantation. Palm Desert, California, 1990 .

$31 \mathrm{Pahl} \mathrm{E}$, Fricker J, Armitage J, et al. Coronary arteriosclerosis in pediatric heart transplant survivors: limitation of longin pediatric heart transplant survivors: limi

32 Ratkovec RM, Wray RB, Renlund DG, et al. Influence of corticosteroid-free maintenance immunosuppression on allograft coronary artery disease after heart transplantation. f Thorac Cardiovasc Surg 1990;100:6-12. 